\title{
O DEBATE SOBRE INTERPRETAÇÃO NA TEORIA DO DIREITO CONTEMPORÂNEA: CONVENCIONALISMO (MARMOR) VERSUS INTERPRETATIVISMO (DWORKIN)
}

\author{
THE DEBATE ON INTERPRETATION IN CONTEMPORARY JURISPRUDENCE: \\ CONVENTIONALISM (MARMOR) VERSUS INTERPRETIVISM (DWORKIN)
}

Lucas Fucci Amato*

\begin{abstract}
Resumo:
Este artigo pretende abordar a visão da interpretação jurídica na teoria do direito contemporânea a partir das críticas que Andrei Marmor dirigiu a Ronald Dworkin. Marmor é um positivista exclusivista, para quem juízos morais não afetam a definição do direito válido. É também um convencionalista, para quem tal definição baseia-se em fatos sociais de reconhecimento da validade pelas autoridades. Ele criticou a visão "interpretativista" de Dworkin sobretudo em duas frentes. Enquanto Dworkin propõe um modelo de interpretação baseado em desacordos teóricos sobre o que o direito requer (em termos morais objetivos), Marmor defende um modelo de interpretação baseado nas intenções do autor (não um sujeito empírico, mas um referente contrafaticamente construído pelo intérprete). Enquanto Dworkin propõe que as explicações da teoria do direito são concorrentes com os juízos práticos dos intérpretes-aplicadores do direito, Marmor procura reafirmar uma posição de observação externa para a teoria do direito, seguindo H. L. A. Hart.

Palavras-chave: Teoria do direito. Filosofia do direito. Interpretação. Ronald Dworkin. Andrei Marmor.
\end{abstract}

\begin{abstract}
:
This paper is about the visions of legal interpretation in contemporary jurisprudence, and approaches the criticism that Andrei Marmor directed to Ronald Dworkin. Marmor is an exclusivist-positivist; in his opinion, moral judgements do not affect the definition of valid law. He is also a conventionalist, then understanding that such definition is based on social facts of recognition of validity by the authorities. He criticized Dworkin's “interpretivist" view, mainly in two points. Whereas Dworkin proposes a model of interpretation based on theoretical disagreements about what the law demands (in objective moral terms), Marmor states an interpretation model based on author's intentions (not of an empirical subject, but of a referent constructed by the interpreter). Whereas Dworkin proposes that jurisprudential statements are in competition with the practical judgements by legal interpreters, Marmor tries to reaffirm a position of external observation for jurisprudence, following $\mathrm{H}$. L. A. Hart.
\end{abstract}

Keywords: Jurisprudence. Philosophy of Law. Interpretation. Ronald Dworkin. Andrei Marmor.

Professor Colaborador, pós-doutor, doutor e bacharel pela Faculdade de Direito da USP, com estágio doutoral como visiting researcher na Harvard Law School e estágio pós-doutoral na Universidade de Oxford. Contato: lucasfamato@gmail.com. 
Introdução

Na esteira de Hobbes - e logo de Bentham e Austin -, os positivistas atacaram o jusnaturalismo. No Diálogo entre um filósofo e um estudante das leis comuns da Inglaterra, Hobbes (1971, p. 16) lapidou a frase: "É a autoridade, não a verdade que faz o direito" (auctoritas non veritas facit legem). O direito não poderia se resumir aos costumes indeterminados dos povos (como na antiga tradição escolástica do direito natural) nem ao exercício individual da razão sobre o que é justo ou injusto (na esteira do racionalismo moderno). Se cada um pudesse tomar tal decisão segundo suas próprias concepções, exercendo seu juízo, recairíamos em uma situação de anarquia. O Estado define então o direito - o conjunto de regras válidas - e as impõem. Pode-se ainda julgar a justiça substantiva de tal direito, mas se trata de uma avaliação moral (sobre o que o direito deveria ser), e não de um juízo sobre o que o direito é.

O positivismo moderno, reinante no século XIX, não pareceria ainda fornecer um porto seguro para a teoria do direito, julgavam seus sucessores. O juiz Oliver Wendell Holmes Jr., da Suprema Corte dos Estados Unidos, definiu o direito como as "profecias sobre o que as cortes farão de fato" (HOLMES JR., 1897, p. 459); em outras palavras, "[1]avado em ácido cínico, cada problema jurídico pode então ser interpretado como uma questão concernente ao comportamento positivo de juízes" (HOLMES JR., 1897, p. 461). Com o intuito de saber o que é o direito, um psicólogo behaviorista e um estatístico ou econometrista poderiam então estudar os padrões comportamentais dos juízes que lhes permitiriam predizer o conteúdo de suas sentenças - e, portanto, definir o que o direito é. O mesmo poderia fazer um neurocientista, estudando a atividade mental dos tomadores de decisões jurídicas. $\mathrm{O}$ direito então ficaria reduzido a comportamentos observáveis a olho nu ou a impulsos elétricos do cérebro. Seria assim objeto de uma ciência séria, exata. Já um sociólogo poderia estudar a classe e a ideologia dos juízes, seu capital cultural e sua origem regional, determinando influências desses fatores na sua posição política, na sua visão econômica e, logo, no conteúdo de suas sentenças. O sociólogo poderia também estudar as práticas sociais efetivas na sociedade, seus costumes fortemente enraizados, e identificar aí o "direito vivo", por oposição às proposições prescritivas da lei e para além do comentário das fontes formais feito pela doutrina (é o que sugeriu Ehrlich em famosa controvérsia com Kelsen sobre qual seria a verdadeira "ciência do direito" - ver AMATO, 2015).

Kant (1998) dizia, entretanto, que o ser humano não está submetido à esfera da necessidade (das determinações genéticas ou sociais, por exemplo), mas também à esfera da liberdade, pois pelo exercício de sua própria razão é capaz de eleger cursos de ação alternativos. Por isso, o direito, assim como a ética, não se resume àqueles 
dados empíricos do mundo. O discurso jurídico desenvolve-se no plano do dever-ser, da normatividade, e não da empiria.

$\mathrm{Na}$ esteira do realismo jurídico americano, alguns seguiram aquela via de estudos empirista. Outros realistas, porém, preferiram continuar a estudar o direito como um discurso sobre regras, mas também sobre propósitos, princípios e políticas públicas (ver AMATO, 2021). Desse modo, os realistas atacaram os formalistas, que resumiam o direito aos conceitos e regras formulados na legislação ou na jurisprudência, com claras hipóteses de incidência e consequências devidas.

H. L. A. Hart foi um autor-chave na reafirmação do positivismo e de um formalismo mitigado, após os ataques realistas. Entre o "nobre sonho" da plena determinação do direito pelas regras positivas e o "pesadelo" do direito indeterminado, a sempre exigir juízos morais e escolhas políticas por parte de seu intérprete (HART, 1983, cap. 4), Hart (1994a, cap. 7) afirmou um formalismo mitigado. Aceitou que as regras, enquanto formulações textuais, têm um núcleo claro de incidência, mas também "zonas de penumbra", instâncias e casos em que sua aplicabilidade suscita dúvidas - aqui o intérprete estaria livre para decidir dentro de sua discricionariedade.

Entretanto, quando Dworkin (1967) lançou a crítica de que o direito não se resumiria a regras, Hart (1994b) acabou por aceitar que padrões morais podem integrar a formação do juízo jurídico quando as regras não são suficientes; princípios podem, assim, preencher as zonas de penumbras das regras ou o campo de discricionariedade do julgador. Com isso, Hart veio a ser definido como um positivista "inclusivo", moderado, para quem juízos morais podem adentrar a interpretação jurídica uma vez que as normas jurídicas válidas tenham se esgotado como fonte primeira da argumentação - a regra de reconhecimento de um determinado sistema jurídico poderia reconhecer isto, uma vez que abrisse zonas de discricionariedade ao intérprete tomador das decisões.

Por oposição, os positivistas "exclusivistas" só aceitam fontes e padrões formais de direitos (regras aprovadas) como critérios decisórios, negando assim que um juízo moral pudesse definir a validade ou invalidade de normas jurídicas. A natureza do direito implicaria essa exclusão desde o princípio. Para os positivistas exclusivistas, todo o direito é validado por este acordo convencional sobre os procedimentos de validação das normas, distinguidas por um pedigree, e qualquer parâmetro normativo que não se remeta a uma fonte formal não pode ser considerado como jurídico (MARMOR, 2002).

Embora não acatasse que a objetividade do juízo jurídico dependesse de um julgamento moral abrangente do intérprete acerca do que aquela ordem jurídica requer (do ponto de vista moral-político), Hart reafirmava a visão pós-realista de que a interpretação jurídica também implica juízos de valor para além daqueles pré-definidos pelo legislador em regras já formuladas e válidas. Não chegava, porém, ao extremo dos positivistas exclusivistas, como Raz (1985; 1972), para quem a autoridade de quem decide o direito 
é razão (formal) que prevalece sobre avaliações ou convicções substantivas sobre o que o direito requer. O positivismo "inclusivo", de Hart e outros (como Jules Coleman e Wil Waluchow), veio então a ser definido ao redor de três teses (HIMMA, 2002):

- a tese do fato social, segundo a qual a existência do direito é distinguida (das normas não jurídicas) por certos tipos de fatos sociais empiricamente verificáveis (para Hart, esse fato é a regra de reconhecimento, como prática social das autoridades, aliada à obediência das regras primárias pelo público - a validade repousa na eficácia);

- a tese da convencionalidade (decorrência da anterior), segundo a qual os critérios de validade das normas jurídicas são convencionais (para Hart, esse critério são as práticas consolidadas de reconhecimento das regras válidas pelas autoridades oficiais, a partir de certos critérios de promulgação que elas reconhecem como conferidores de um caráter formal ao direito, isto é, como constitutivos de sua validade);

- a tese da separabilidade, segundo a qual não há coincidência necessária entre as prescrições jurídicas e morais (e, portanto, a imoralidade de uma regra não afeta sua validade jurídica).

Dworkin veio a suceder Hart no ensino de teoria do direito na Universidade de Oxford. Entretanto, a crítica de Dworkin a Hart não parou por aí (ver SHAPIRO, 2007). Ao menos dois pontos, que para Hart pareciam uma solução com relação ao positivismo do século XIX e ao realismo do século XX, foram alvos de ataque por parte de Dworkin.

Primeiramente, Hart (1994a, p. v) definiu seu trabalho como um "ensaio de sociologia descritiva", dentro da "teoria jurídica analítica". Com isso, contra a visão crua do direito da teoria imperativista de John Austin, que resumia o fenômeno jurídico a comandos do soberano obedecidos pelos súditos (HART, 1994a, cap. 2; 1994a, p. 8891), veio a definir como enfoque privilegiado para a teoria do direito analítica um "ponto de vista externo" moderado: nem o engajamento direto na ordem jurídica sob análise (o argumento moral e controverso levantado pelos intérpretes práticos: doutrinadores, advogados, juízes) - um "ponto de vista interno"; nem o ponto de vista externo extremo, do cientista behaviorista, incapaz de entender a interpretação e argumentação jurídica. Só de um ponto de vista moralmente desengajado, mas compreensivo (que compreendesse as "regras do jogo", embora não se estivesse em campo) seria possível garantir a objetividade e acuidade, por exemplo, de uma distinção como aquela entre a situação de "ser obrigado" a algo e de "ter a obrigação" disto, isto é, entre um comando qualquer e uma exigência normativa - que, no caso do direito, toma a regra jurídica válida como razão de uma conduta (obrigatória, proibida ou permitida) ou de sua justificação (ver MICHELON JÚNIOR, 2004).

Dworkin (2004) veio a atacar tal "arquimedianismo", tal pressuposto do ponto de vista externo moderado como apoio adequado para a teoria do direito. Para 
Dworkin (2004), tanto o teórico do direito quanto o jurista prático fazem argumentos sobre o que o direito requer - nessa medida, com maior ou menor abstração, engajam-se em controvérsias valorativas, que no fundo pressupõem a articulação de certa moralidade política. Por isso, o que caracterizaria o direito são os "desacordos teóricos" emergentes para além do acordo sobre questões fáticas: normas aplicáveis e circunstâncias concretas (DWORKIN, 1986, p. 5). Nesse sentido, não se trata apenas de discernir diferentes tipos de normas jurídicas, como regras e princípios (objeto da preocupação de DWORKIN, 1967); no fim das contas, para Dworkin (2006, p. 4), "[a] ideia do direito como um conjunto de diretrizes pontuais, que podemos em princípio individualizar e contar, parece-me uma ficção escolástica". A visão positivista do sistema jurídico (legada pelos jusracionalistas e romanistas) parece ter caído por terra como um todo, diante da concepção do direito como prática argumentativa de fundo moral.

O outro ponto que Hart (1994a, cap. 5) avançou foi a tese das fontes sociais do direito. Entendido como um sistema de regras primárias (de conduta) e regras secundárias (de julgamento e alteração do próprio direito), o direito seria definido ainda por um tipo especial de regra secundária: a "regra de reconhecimento". Não se trata de uma regra jurídica no sentido jurídico-positivista de validade, mas de uma prática social reiterada das autoridades do direito, prática esta que definiria o que conta como fonte formal do direito e o que não conta: o que é válido e o que não é. Em polêmica com Fuller, Hart defendeu que não se tratava de pré-julgar moralmente o que deveria ser validado como direito, mas sim que o conceito de regra de reconhecimento simplesmente descrevia (daquele ponto de vista desengajado, "externo" mas compreensivo, interpretativo) as práticas sociais das autoridades jurídicas (ver AMATO, 2019).

Dworkin (1972; 1986, cap. 4) igualmente atacou tal concepção, contestando que o conceito de direito pudesse ser definido de tal maneira empírica, descritiva, e não de um ponto de vista interno. Para Dworkin era preciso sempre adotar tal visão de dentro, que explica o direito como uma prática social normativa, um campo de exercícios interpretativos em que não somente se considera a busca a melhor interpretação possível (a mais forte, racional e convincente) dos textos jurídicos (legislativos e jurisprudenciais) - seguindo-se o "princípio da caridade" filosófica/linguística -, mas também se visa, necessariamente, ao que é moralmente adequado dentro da teia de referência de sentidos e valores que informa o próprio significado daquela prática interpretada - o direito.

Um sociólogo compreensivo, na linha de Weber, poderia apreender e descrever o sentido das práticas que interpreta, ainda que delas não participasse - esse seria o limite da visão "hermenêutica" de teoria do direito avançada por Hart (MACEDO JÚNIOR, 2013a, cap. 3). Um etnógrafo preocupado em captar o "saber local” (GEERTZ, 1997; 1973), descrevendo como determinada comunidade "autointerpreta" suas práticas, inserindo-as na teia de valores e cosmovisões dessa comunidade de vida e identificando 
as semelhanças de família entre as concepções que compõem tal teia valorativa, pode mitigar seu ponto de vista exterior (digamos, sua moralidade cristã, seu individualismo ocidental ou seu liberalismo) e dar voz aos próprios sujeitos pesquisados. O que Dworkin (1986) exige para o teórico e o prático do direito é mais que isso: para explicar o direito de modo mais ou menos abstrato, circunscrito a controvérsias concretas ou "em tese", o intérprete precisa formular argumentos considerando o que o direito requer. Seu objeto de interpretação, então, não se resume a um conjunto de formulações textuais de fontes formais, embora deva incluir o corpo de direito formal. $\mathrm{O}$ intérprete precisa formular concepções normativas, morais, coerentes com esse referente, mas que podem por vezes até mesmo implicar a desconsideração de um referente normativo que um positivista consideraria como "norma válida", mas que na verdade não se adequa substancialmente à unidade de valor que o intérprete identifica naquela prática social e ancora na (quase) totalidade de suas expressões textuais autoritativas. Com isso, a própria interpretação pode ter um caráter reformador do corpo de direito objetivo sob análise - afastando o que, a princípio, formalmente, seria um critério decisório válido.

É com esses pressupostos que se desenvolve o debate entre a visão convencionalista-positivista do direito e a proposta interpretativista pós-positivista (sobre este debate, ver MACEDO JÚNIOR, 2013b). Neste trabalho, discutem-se as objeções que Marmor (2005), em seu livro Interpretação e teoria do direito, faz a Dworkin, principal construtor de uma visão interpretativa de teoria do direito. ${ }^{1}$ Trata-se da segunda edição de um livro derivado de tese de doutorado que Andrei Marmor apresentou à Faculdade de Direito da Universidade de Oxford. Seu objeto de estudo é sobretudo a visão madura de teoria do direito de Dworkin (1986), consolidada no livro O império do direito.

Marmor é um positivista exclusivista, que nega que critérios morais possam definir a validação das normas jurídicas. Como os positivistas em geral, Marmor também aceita a tese hartiana de uma fonte convencional de reconhecimento da validade, mas rejeita a abertura que Hart (1994b) veio a admitir (após a crítica de Dworkin) em relação a juízos morais.

Em sua crítica a Dworkin, Marmor (2005) pretendeu reafirmar a visão convencionalista do direito e propor um modelo de interpretação jurídica baseado nas intenções do autor (não de um autor real, mas de um autor construído pelo intérprete), enfrentando portanto a tese dworkiniana de que o direito é uma série de práticas interpretativas que envolvem, em situação de conflito, a busca da resposta correta, isto é, daquela que objetivamente expressa a coerência moral em que se funda determinada ordem jurídica - a qual não se resume, portanto, a um conjunto pré-ordenado de normas

Agradeço a Ronaldo Porto Macedo Júnior pelas indicações bibliográficas e comentários a uma versão anterior deste trabalho. 
formalizadas, reconhecidas convencionalmente e tomadas como critério único para a interpretação.

Inicialmente, apresentam-se cinco séries de críticas. Analisam-se em maior profundidade as críticas de Marmor (1) à rejeição, por Dworkin, de um modelo de interpretação baseado nas intenções do autor da obra interpretada e (2) à "tese hermenêutica" dworkiniana, que defende a concorrência entre os juízos avaliativos do teórico e do prático. Finalmente, apresentam-se outras considerações sobre a contenda entre esses autores. A tese do trabalho é de que as objeções de Marmor afinal não foram convincentes a pontos de adicionar uma defesa do positivismo convencionalista mais forte do que aquela já apresentada pelo próprio H. L. A. Hart.

A crítica de Marmor ao interpretativismo de Dworkin

O livro de Marmor Interpretação e teoria do direito busca "re-examinar o positivismo jurídico à luz" do "desafio interpretativo" de Dworkin (MARMOR, 2005, p. 8). Para Dworkin (1986), a visão convencionalista do direito o apresenta como mero fato social, determinado apenas por convenções. A resposta à questão "o que é o direito", nas teorias convencionalistas, reporta-se a fatos, a decisões de autoridades que criam regras válidas, jurídicas. Dworkin sustenta que tal visão é incompatível com a natureza argumentativa e controversa do direito enquanto prática social. Segundo os convencionalistas, ainda, não haveria resposta jurídica determinável em casos controversos, aos quais os padrões normativos válidos, positivados, não dessem solução definida. Para Dworkin, há solução jurídica nestes casos, pois o direito não se resume a convenções (ou ao que poderíamos chamar, em termos não dworkinianos, de "fatos institucionais", como a promulgação de uma lei ou o proferimento de reiteradas sentenças reconhecidas como uma jurisprudência consolidada). O direito é, para Dworkin, uma atividade interpretativa - abrange padrões não institucionalizados, que não foram objeto de decisão por autoridade competente anterior, mas que guardam coerência valorativa e adequação com o corpo de regras interpretado.

Para responder a Dworkin em defesa de uma posição convencionalista, Marmor recorre a uma série de teorias da verdade, do conhecimento e da linguagem, buscando oferecer uma alternativa à concepção dworkiniana da interpretação. Porém, a crítica central autoproclamada do livro de Marmor (2005, p. 7-8) é mostrar que o argumento de Dworkin contra o convencionalismo, mais do que uma crítica metodológica, é um desafio completo ao convencionalismo e que a teoria da interpretação de Dworkin não é (apenas) uma alternativa às teorias convencionalistas de interpretação ("semânticas"), mas sim uma nova concepção geral de teoria do direito. 
Do itinerário da crítica de Marmor a Dworkin e de sua tentativa paralela de oferecer uma teoria convencionalista que responda ao desafio interpretativista de Dworkin, destaco cinco séries de argumentos: (1) crítica à interpretação de Dworkin sobre o "aguilhão semântico"; (2) a crítica ao conceito de coerência em Dworkin; (3) a crítica quanto à visão de que o direito sempre exige interpretação; (4) a crítica ao modelo interpretativo (ou "interpretivo") dworkiniano, em favor de um modelo de interpretação de intenções de um autor contrafaticamente construído pelo intérprete; (5) a crítica à "tese hermenêutica" de Dworkin, que defende que práticos e teóricos do direito produzem argumentos concorrentes, pois todos interpretam o direito à sua melhor luz.

O primeiro conjunto de argumentos desafia a crítica de Dworkin às "teorias semânticas do direito". Dworkin atribui a Hart a pretensão de definir o conceito de direito por meio de uma descrição do significado da palavra "direito". O "aguilhão semântico" (DWORKIN, 1986, p. 45-46) que aferroa tais teorias as faz identificar o direito a fatos históricos, a decisões institucionais. Ao teórico caberia descrever os usos que o prático faz da palavra "direito". Essa pretensão teórica, para Dworkin, teria de ser substituída por uma concepção interpretativista do direito, capaz de dar conta da realidade das controvérsias jurídicas, que não são meras disputas verbais, mas envolvem inclusive engajamentos em desacordos teóricos (sobre o que o direito requer, ainda que não haja dúvida quanto à identificação de regras aplicáveis e fatos sob julgamento). Marmor responde a essa crítica de Dworkin por duas séries de argumentos:

- 1) o projeto teórico de Hart e da teoria do direito analítica não assume as premissas que Dworkin lhes imputa (não busca simplesmente uma descrição dos usos da palavra direito, nem a definição dos critérios para tal uso) (MARMOR, 2005, cap. 1);

- 2) os positivistas como Hart não são semânticos no sentido do realismo filosófico, não buscam a "essência” do direito para além das convenções - pelo contrário, resumem-no a elas (MARMOR, 2005, cap. 5).

Este primeiro bloco de críticas a Dworkin, portanto, reitera a tese de Marmor de que a teoria de Dworkin não é apenas um desafio às teorias semânticas do direito (ou ao "aguilhão semântico" dos convencionalistas), mas sim uma contestação do convencionalismo jurídico em geral.

O segundo bloco de críticas volta-se à tese dworkiniana da coerência, que afirmaria pertencerem ao direito não apenas as regras postas por autoridade competente, mas também os padrões normativos com elas coerentes (que, devido a esta coerência, não seriam apenas morais, mas, sobretudo, juridicamente vinculantes). Para Marmor (2005, cap. 4), o conceito de coerência é importante na teoria do direito de Dworkin em dois níveis, dificilmente conciliáveis: o do conteúdo (como um valor de moralidade política) e o do método (de interpretação, especialmente na etapa “pós-interpretativa”). Para Marmor, na 
teoria de Dworkin a coerência seria uma exigência de equidade, esta por sua vez um valor de caráter fundacional, ancorado em convicções morais substantivas. Isto é, na verdade, inverossímil e incompatível com os propósitos da teoria de Dworkin. Nossas convicções sobre a adequação de uma interpretação devem ser independentes de julgamentos de valor substantivos, a fim de que possamos distinguir interpretação de invenção; mas o “direito como integridade" (DWORKIN, 1986, cap. 6-7) é uma interpretação de fundo moral, de modo que não fornece um critério independente para o juízo de adequação da interpretação.

Quanto ao terceiro argumento, Marmor imputa a Dworkin a visão de que o direito sempre precisa ser interpretado; e defende, ao contrário, que a interpretação no direito é excepcional. A posição de Marmor (2005, p. 118) é de que, em sentido próprio, a "interpretação é exigida apenas quando a formulação da regra deixa dúvidas sobre sua aplicação a um dado conjunto de circunstâncias". Em outros termos, a interpretação designa uma atividade de atribuição de sentido mais específica que a simples explicação. O modo normal de comunicação e entendimento da linguagem no direito envolve simplesmente seguir regras, aplicá-las, mas não interpretá-las; a interpretação só surgiria para resolver uma situação subdeterminada convencionalmente, em que as fontes autoritativas de validade não determinassem diretamente o resultado do juízo sobre um caso. Marmor repete esta tese e busca sustentá-la em diferentes fundamentos, dos quais destaco dois.

Uma sustentação do conceito restrito de interpretação é buscada na distinção entre casos fáceis (determinados pelos padrões jurídicos existentes) e casos difíceis (sem solução direta pelas normas jurídicas válidas), que para Marmor (2005, p. 95) caracteriza a posição positivista/convencionalista, em conexão com a tese de que o direito "como é" é independente do direito "como deve ser". Desta forma, o juiz poderia identificar o direito (as regras válidas) e aplicá-las sem considerar o que o direito "deveria ser" naquelas circunstâncias.

A distinção entre casos fáceis e difíceis (ver DWORKIN, 1975) pode ser tomada em paralelo com a distinção entre "núcleo" (onde a linguagem é determinante do resultado) e "penumbra" das regras (zona de indeterminação linguística, que requer interpretação) (MARMOR, 2005, p. 96). Assim, para um positivista, o direito nem sempre requer interpretação (MARMOR, 2005, p. 95). Para Marmor (2005, p. 101), as considerações de Wittgenstein sobre a conduta de "seguir uma regra" (rule-following) dão sustentação à distinção hartiana (HART, 1994a, cap. 7) entre o núcleo e a penumbra das regras - na penumbra, há subdeterminação convencional do significado; portanto, casos que caem na zona de penumbra das regras (e só aí) urgem interpretação, já que não é possível aplicação direta da regra ao caso.

"Se esgotei as justificações, então atingi a rocha dura e minha pá entortou. Então estou inclinado a dizer: "é assim que eu ajo'." (WITTGENSTEIN, 1999, § 217). 
Não há mais regra a seguir nem a interpretação é capaz de solucionar a controvérsia sobre regras e apontar qual é a regra; é preciso criar nova regra, por interpretação (ver HERSHOVITZ, 2002).

Ainda com vistas a sustentar seu conceito restrito de interpretação, Marmor apresenta uma defesa de Hart diante de um contra-argumento de Fuller. A tese de Fuller de que só se pode compreender a regra tendo em vista seu propósito ${ }^{2}$ violaria a distinção entre seguir uma regra e interpretá-la: para segui-la, basta agir de acordo com a regra, com a intenção de fazê-lo; a antecipação argumentativa do propósito só ocorre quando a regra - o padrão de comportamento convencional - não se aplica diretamente ao caso, e se torna preciso construir uma nova regra (MARMOR, 2005, p. 117).

$\mathrm{O}$ foco deste trabalho serão o quarto e o quinto conjuntos de críticas de Marmor a Dworkin: a crítica ao modelo de interpretação "interpretativa" e à "tese hermenêutica".

O debate Marmor-Dworkin: duas críticas (e possíveis réplicas)

Consideram-se as críticas ao modelo de interpretação dworkiniano e à "tese hermenêutica" relevantes por três motivos: (a) em contraste com as críticas anteriores; (b) pela própria centralidade desses dois aspectos no modelo de Dworkin, em polêmica com os convencionalistas; (c) pela resposta que Marmor dá ao modelo dworkiniano, sustentando uma alternativa convencionalista a Dworkin.

Quanto ao contraste com as críticas supracitadas (a):

1) A primeira crítica, de que Dworkin (1986, cap. 2) erraria na caracterização das teorias "semânticas" do direito - por que estas não se prendem a uma disputa verbal sobre o significado da palavra "direito" -, é convincente, embora trivial. De fato, parece claro que Hart não procura simplesmente definir o significado ou os usos da palavra "direito", mas busca compreender o direito como uma prática social ancorada em fatos institucionais (de um ponto de vista não moralmente engajado, mas que reconheça a dinâmica da interpretação e argumentação jurídica, baseada em textos e

Fuller (1971) defende uma prática prudencial de "fidelidade ao direito", que começa com a observação de que, mais do que interpretar palavras, os tomadores de decisão jurídica interpretam instituições: parcialmente reveladas pelos textos jurídicos criados, parcialmente sustentadas por expectativas amplamente difundidas, a normatividade tácita, o "direito implícito". Em debate com Hart (1958), Fuller (1958) indicava que regras formais apenas conduzem racionalmente a justificação das decisões se interpretadas por referência a propósitos - isto é, finalisticamente. Por exemplo, a regra "proibido veículos no parque" certamente inclui em sua proibição carros circulando no local ("carros" estão no "núcleo de certeza" da regra, nos termos de Hart (1994a, cap. 7). Mas e triciclos ou patinetes? E um caminhão da segunda guerra mundial, estacionado no meio do parque, em memória daqueles acontecimentos? Para saber se a proibição se aplica, precisaremos definir se o propósito da regra é a segurança dos pedestres ou é evitar a poluição sonora, por exemplo. Ver também Unger (1996, p. 59-63), sobre o raciocínio analógico. 
no exercício da discricionariedade quando esses textos - fontes formais do direito - não ofereçam orientação unívoca para sua decisão). O alvo de Dworkin tampouco é contestar a definição da palavra "direito", mas sim considerar que o conceito de direito denota um campo mais abrangente de juízos (normativos, morais) do que a referência denotativa a uma série estrita de padrões normativos textualmente formulados, pré-decididos e, assim, pré-selecionados, aos quais um intérprete devesse resumir sua indagação sobre o que o direito requer.

2) A segunda crítica, ao conceito de coerência, de fato enfoca uma noção central na teoria de Dworkin. Mesmo que seja convincente, não oferece um ponto para a polêmica com o positivismo ou o convencionalismo. Apenas, potencialmente, um defeito interno da teoria dworkiniana.

3) A terceira crítica, de que Dworkin defenderia que o direito sempre precisa ser interpretado (MARMOR, 2005, p. 27), não é convincente. Se Marmor defende que a interpretação é excepcional no direito, Dworkin também parece acreditar que a interpretação no sentido forte, a aplicação "interpretativa", também não é rotineira embora sempre esteja potencialmente contida na aplicação do direito, vindo à tona assim que surja uma controvérsia teórica (daí que não se trate de casos periféricos, "difíceis", sobre a "penumbra" das regras, mas sim de casos "pivotais", que merecem atenção e devem ser cobertos pela teoria) (DWORKIN, 1986, p. 41-43). Os juízes nem sempre são demandados a filosofar, mas no limite podem ter sob seu juízo questões morais controversas que exigem um tipo de análise conceitual qualitativamente afim à prática da filosofia, ainda que mais circunscrita (DWORKIN, 2010).

No que se refere ao fato de a crítica ao modelo interpretativo e à "tese hermenêutica" tocarem pontos sensíveis e centrais na teoria dworkiniana, em sua polêmica com o positivismo (b), é saliente que o modelo da interpretação "interpretativa" é o corolário da teoria do direito de Dworkin, em vinculação com a "tese hermenêutica", que justamente defende o cabimento desse tipo de interpretação tanto à teoria quanto à prática (argumentativa) do direito. São grandes pontos de contraste entre Dworkin e os convencionalistas, o primeiro dizendo respeito a cingir a atividade do intérpreteaplicador do direito à remissão às fontes convencionais (sem dar valor jurídico à "moralidade política" a elas inerente) e o segundo, à visão que Dworkin (2004) acusa de “arquimediana”, de defender uma espécie de argumentação teórica (descritiva) distinta da argumentação normativa das controvérsias práticas do direito.

Igualmente, trata-se de dois pontos de contraste com Marmor (c). De um lado, Marmor (2005) defende uma alternativa convencionalista ao modelo "interpretativo" ou de "interpretação construtiva" dworkiniano, sustentando que a rejeição de Dworkin ao modelo de remissão à intenção do autor não cobre a alternativa defendida por Marmor: atribuição contrafática de intenções a um autor fictício, construído pelo intérprete (e não 
pesquisa psicológica ou sociológica empírica das reais intenções de um autor concreto). De outro lado, Marmor (2005) tenta recusar o "arquimedianismo", mas defende a diferença entre uma teoria sensível aos valores da prática social que observa e a própria prática valorativa observada; seu ponto central é que a teoria, ao contrário da prática, não precisa apresentar o direito sob "a melhor luz moral".

A controvérsia sobre a intenção do autor

Esta crítica de Marmor segue o seguinte encadeamento: 1) elabora um modelo de interpretação referida às intenções do autor da obra interpretada; 2) mostra que Dworkin rejeita que a interpretação possa repousar na busca das intenções do autor, mas que a crítica dele não cobre o modelo formulado por Marmor (que diz respeito à atribuição contrafática de intenções, não à descoberta das intenções reais); 3) defende a incompatibilidade da "interpretação construtiva" esposada por Dworkin com o direito. A resposta de Dworkin poderia se encaminhar no sentido de que o modelo de Marmor se trata de mais uma hipótese interpretativa, insuficiente por si só, mas abarcada no seu modelo "interpretativo" ou "construtivo".

Marmor (2005, p. 25) define interpretação como a imposição de significado a um objeto, significado este que diz respeito a intenções de comunicação, intenções estas que podem ser atribuídas contrafaticamente a um falante fictício, cuja caracterização traz em si os critérios do sucesso da interpretação. $\mathrm{Na}$ verdade, os atributos do autor fictício constituem um quadro de referência que define os parâmetros usados na interpretação (MARMOR, 2005, p. 23).

Essa forma de interpretar oferece duas vantagens. Em primeiro lugar, corrobora a tese de que a interpretação é excepcional e parasitária em relação a um conhecimento prévio dos significados literais da comunicação - só se interpretam os aspectos da comunicação não suficientemente determinados por regras ou convenções (MARMOR, 2005, p. 25). Em segundo lugar, o modelo de atribuição contrafática de intenções é alternativo aos modelos tanto das intenções reais do falante quanto do propósito do intérprete. Poder-se-ia mesmo dizer que a atribuição de intenções contrafáticas não diz respeito a intenções, se as definirmos como eventos mentais. A tese de Marmor (2005, p. 24-25) apenas quer explicar a gramática da interpretação, sendo indiferente ao fato de a interpretação designar ou não um evento mental. A diferença lógica entre a atribuição contrafática e real de intenções reside na natureza das condições de verdade das respectivas afirmações.

Já o modelo de interpretação de Dworkin tem como cerne, em suas palavras (DWORKIN, 1986, p. 52), o seguinte: “a interpretação construtiva é uma questão de impor um propósito a um objeto ou prática de forma a fazê-lo o melhor exemplo possível 
da forma ou gênero ao qual se considera que ele pertença”. Para Marmor (2005, p. 29), porém, a única alternativa aventada por Dworkin na sustentação de seu modelo seria aquela da busca pelas reais intenções do autor. Segundo este modelo das intenções do autor, "interpretar é nada mais que uma tentativa de recuperar as reais intenções, propósitos, etc., que o autor do texto relevante [sob interpretação] efetivamente teve com relação aos vários aspectos do sentido deste" (MARMOR, 2005, p. 29).

Segundo Marmor (2005, p. 29-31), Dworkin opõe duas críticas ao modelo de interpretação como verificação das intenções reais do autor: 1) o argumento de que os artistas (arquétipos dos criadores em geral) tipicamente querem que suas obras se tornem objetos com um valor cultural próprio, independente dos propósitos e intenções originais de seu autor; 2) a concepção de que a interpretação é gênero-dependente, isto é, de que interpretar significa apresentar o objeto interpretado como o melhor exemplo possível de seu tipo, do gênero a que se pode considerar que pertence. Quanto ao primeiro argumento, critica Marmor (2005, p. 30), não pode ser assumido com certeza para a interpretação artística (artistas podem querer que suas intenções sejam consideradas) e, no que diz respeito ao direito, não se sustenta faticamente (por exemplo, parece óbvio que um legislador deseje que seus propósitos e intenções relacionados à lei que aprovou sejam considerados na interpretação desta lei). Quanto ao segundo argumento, Marmor (2005, p. 31) concorda que os valores associados ao gênero determinam de maneira parcial, mas crucial, o sentido atribuível ao objeto.

Dessa forma, para Dworkin (1986, p. 60-61), o argumento da intenção do autor é uma referência sobre o valor que existe na arte; a correção desse argumento depende de o objeto artístico ter o valor que sua apresentação interpretativa propõe. Este é o foco da interpretação - a atribuição de valor à luz da qual se avalia o objeto interpretado. Entretanto, o modelo pragmático de Marmor, centrado na construção de um falante hipotético, tem - segundo Marmor (2005, p. 28) - um ponto de partida similar ao de Dworkin, ao defender que à interpretação interessam intenções ou propósitos: não as intenções ou propósitos arbitrariamente impostos pelo intérprete, nem os estados psicológicos idiossincráticos do autor, mas aqueles plasmados na obra e expressáveis enquanto atributos de um autor hipotético construído pelo intérprete.

Dworkin não teria considerado este modelo de atribuição contrafática de intenções a um autor (MARMOR, 2005, p. 29). Mas esta seria a única alternativa capaz de dar conta dos propósitos ou intenções plasmados no objeto ou prática social interpretado e, ao mesmo tempo, da natureza autoritativa do direito. A crítica de Marmor (2005, cap. 6) ao modelo de interpretação de Dworkin assume aqui a tese de que a "interpretação construtiva" (postulada por Dworkin) é incompatível com o caráter autoritativo do direito, ao postular a integração, ao corpo do que é direito, de normas que não foram elas mesmas objeto de decisão por autoridade competente e, por isso, não eram tidas desde 
o início como normas jurídicas. São "objetos" sobre os quais não se pode considerar a possibilidade de terem sido criados com a intenção de serem direito vinculante. Para Marmor (2005, p. 80-81), ao contrário, para ser considerado direito, precisamos poder interpretar um enunciado normativo como tendo sido criado com a intenção de ser jurídico (a atribuição dessa intenção "jurígena”, ainda que contrafática, tem que ser possível). Aqui há uma vinculação à tese de Raz (1985, p. 299-300; cf. MARMOR, 2005, p. 87) de que o direito deve poder possuir autoridade para que possa clamá-la (as razões vinculantes do direito são mediadas pelo intérprete, cuja autoridade deve poder ser legítima aos olhos dos destinatários do direito). Do contrário, não haveria possibilidade de legitimação. Por isso, os padrões normativos que não foram objeto de decisão, que não foram criados como jurídicos, não podem ser considerados autoritativos e vinculantes (RAZ, 1985, p. 310; MARMOR, 2005, p. 93).

Qual seria uma resposta plausível de Dworkin a este conjunto de críticas de Marmor? Comecemos pela última objeção: sobre a natureza autoritativa do direito. Dworkin não desconhece o caráter institucional da prática social que é o direito e afirma que o point valorativo dessa prática é um ideal de justiça política. Seu modelo interpretativo visa justamente a dar conta dessa exigência de justificação: as exigências de adequação (fit) e justificação apresentadas como dimensões de seu modelo "interpretativo" dão sustentação a valores-chave de fundo político-moral, como a equidade procedimental (expressa na dimensão de adequação) e a justiça substantiva, "que é o nervo da justificação política" (DWORKIN, 2004, p. 25). Esses valores, ressalta Dworkin (2004), integram e vão além do valor estrito da legalidade, único reconhecido pelo positivismo. Ao espantar a sombra da discricionariedade que surgiria em casos subdeterminados convencionalmente, para os quais as regras não oferecem decisão determinada, Dworkin justamente leva a sério o caráter autoritativo do direito, adensando a exigência de legitimação da autoridade decisória com base no dever de apresentar o direito "à sua melhor luz". Por isso é que, quando esses parâmetros convencionais não circunscrevem uma solução, o intérprete precisa buscar (isto é, construir argumentativamente) o espírito valorativo que embasa todo aquele corpo de direito.

Sobre o modelo de intenção do autor contrafaticamente atribuída, defendido por Marmor, Dworkin poderia responder que se trata de mais uma instância do processo interpretativo que ele (Dworkin) defende, mas que é insuficiente para colocar o intérprete na posição de produzir argumentos normativos substanciais sobre a prática interpretada. Afinal, a construção do autor fictício em Marmor é uma aproximação à "hipótese interpretativa política" que o jurista precisa elaborar na visão de Dworkin (1982) - por exemplo, para construir o sentido acumulado de uma tradição jurisprudencial, como se escrevesse um "romance em cadeia". Mas não se trata apenas de uma disputa verbal. Os modelos interpretativos não se equivalem. O modelo de Marmor parece tentar 
salvar uma velha distinção defendida pelos "intencionalistas" (cf. DWORKIN, 1982, p. 188): a possibilidade de se compreender o significado de uma obra sem, simultânea e indissociavelmente, formular um juízo sobre ela. A observação externa e desengajada do que seu autor - real ou hipotético - quis ou parece ter intencionado. As intenções e propósitos do autor podem mesmo ser atribuídos contrafaticamente a um autor "construído" pelo intérprete, como quer Marmor. A questão é que tal atribuição exige a formulação de hipóteses e testes de coerência e adequação com o significado possível da obra interpretada; sobretudo, a diferença está em que o intérprete dworkiniano necessita mostrar o point valorativo (no caso do direito, um valor político) que o objeto interpretado pode representar. Isto exige do intérprete argumentos avaliativos que não podem ser escondidos por detrás de um empreendimento de "construção" de um autor hipotético ou fictício, mas que precisam ser expressos no mesmo plano das controvérsias práticas (doutrinárias, jurisprudenciais) sobre o que o direito exige em um caso concreto. A sustentação por Marmor da possibilidade - que Dworkin explicitamente rejeita - de compreender o significado sem julgar o valor da prática faz mais sentido ainda quando conjugada com a crítica de Marmor à "tese hermenêutica”, discutida a seguir.

A controvérsia sobre a "tese hermenêutica"

Qual é, afinal, a visão dworkiniana da interpretação jurídica? Analiticamente, podemos distinguir três etapas do exercício interpretativo (DWORKIN, 1986, cap. 2; cf. MACEDO JÚNIOR, 2013a, p. 228-234). A primeira é a fase "pré-interpretativa" e exige a seleção do material bruto para a interpretação: por exemplo, conjuntos de regras e casos paradigmáticos que já são consensualmente tomados como objeto típico da interpretação. $\mathrm{Na}$ etapa interpretativa propriamente dita, o intérprete precisa justificar os principais elementos daquela prática identificada na etapa pré-interpretativa. Então, a etapa interpretativa é o momento dos juízos sobre a adequação (fit) das justificativas às práticas. É o momento da justificação com os apelos valorativos. Finalmente, na etapa "pós-interpretativa" ou "reformadora", o "intérprete ajusta o seu senso daquilo que a prática 'realmente' exige para melhor servir à justificativa que ele aceita na etapa interpretativa" (DWORKIN, 1986, p. 66). Nessa etapa pós-interpretativa, é o momento em que há maior grau de controvérsia, mas é nessa hora que o intérprete precisa finalizar uma concepção internamente coerente nos seus argumentos. Na realidade, essas etapas de interpretação são menos evidentes e destacadas, são mais uma questão de ver, "à primeira vista", as dimensões de uma prática, seu propósito e a consequência pós-interpretativa deste propósito.

Aqui, a crítica de Marmor visa à "tese hermenêutica” esposada por Dworkin, segundo a qual o participante da prática jurídica e o teórico devem adotar o mesmo ponto 
de vista normativo, produzindo argumentos concorrentes, no mesmo nível (adotando "o mesmo ponto de vista normativo" - MARMOR, 2005, p. 40), sobre esta prática, o que significa interpretá-la, construir seu significado apresentando-a "sob a melhor luz moral" (MARMOR, 2005, p. 43).

Na visão de Marmor (2005, p. 27), Dworkin elabora um argumento substantivo e um argumento metodológico. O primeiro sustentaria que toda conclusão sobre qual é o direito em determinado caso (ou sobre o que é lícito) é resultado de interpretação, que necessariamente envolve considerações valorativas, pois interpretar um objeto é apresentá-lo à sua melhor luz. Portanto, toda conclusão sobre qual é o direito envolveria considerações avaliativas.

$\mathrm{O}$ argumento metodológico é aquele que solapa a distinção entre a interpretação prática do direito (o que é jurídico/lícito em dado caso, qual é o direito em dadas circunstâncias) e a teoria do direito (o que é "o direito" em abstrato). Em ambos os casos, teoria e prática, tem-se interpretações do direito, que é em si uma prática social argumentativa. Tanto juízes quanto teóricos interpretam tal prática social ao apresentá-la sob a melhor luz moral - ambos estão engajados (sempre para Dworkin) em um mesmo tipo de raciocínio e produzem argumentos concorrentes, no mesmo nível de observação.

Partindo do exemplo do vegetariano que quer defender normativamente sua posição diante de um carnívoro, produzindo os melhores argumentos morais, Dworkin defende que tanto os participantes dessa controvérsia quanto o teórico que buscasse descrevê-la teriam que interpretar o que o vegetarianismo "realmente exige" (DWORKIN, 1986, p. 64; MARMOR, 2005, p. 41). Marmor (2005, p. 41-42) entende que este é o principal argumento de Dworkin em defesa de sua "tese hermenêutica", mas que ele engloba dois aspectos. O primeiro deles é de que a explicação do direito, tomado como uma prática social, é interpretativa - portanto, valorativa. Isto não é contestado por Marmor, mas sim o segundo aspecto do argumento dworkiniano: de que a interpretação especificamente de uma prática argumentativa como o direito é um empreendimento avaliativo, o que exige do intérprete juízo avaliativo sobre os próprios valores que interpreta (assim como ocorre com os participantes da prática ao disputarem seu significado). Para Marmor (2005, p. 42), “[o] que Dworkin parece ignorar aqui é que há uma diferença crucial entre formar uma visão sobre os valores manifestos em uma prática social, como o direito, e realmente ter julgamentos avaliativos sobre ela". Assim, para Marmor, há uma necessidade do intérprete, do observador “externo", de ter uma visão teórica sobre os valores imanentes a uma prática, para que possa compreender como as exigências dessa prática fazem sentido a seus participantes. Disso não decorre, porém, a formação de um juízo valorativo sobre tais exigências - a explicação dos valores que dão sentido à prática argumentativa observada (como a discussão do vegetariano com o carnívoro) não compromete seu intérprete (teórico) com tais valores (MARMOR, 
2005, p. 42-43). Para Marmor (2005, p. 43), a diferença negada do argumento teórico em relação ao argumento prático daqueles que estão em desacordo "teórico" só pode ser explicada pela tese dworkiniana de que qualquer interpretação deve esforçar-se para apresentar seu objeto sob sua "melhor luz, tudo considerado" (DWORKIN, 1986, p. 53). Porém - e aqui se encontra o núcleo da crítica de Marmor (2005, p. 43) -, para o prático a melhor interpretação possível é a melhor interpretação moral; já para o teórico apresentar seu objeto como o melhor exemplo do gênero não significa necessariamente a melhor interpretação moral - se "o melhor exemplo possível" é "o melhor moral" isto depende dos propósitos da teoria, é uma coincidência totalmente contingente.

Qual seria uma resposta verossímil de Dworkin a tal crítica? Em primeiro lugar, parece tratar-se de mais uma versão de "arquimedianismo": a visão de que o teórico do direito pode se resumir a reportar os significados atribuídos à prática por seus participantes, sem que ele mesmo - o teórico - tenha que produzir argumentos não meramente descritivos, mas também igualmente normativos ou avaliativos, tais como os dos participantes da controvérsia (no caso do direito, argumentos normativos dizem respeito às exigências da moralidade política).

$\mathrm{O}$ argumento de Marmor parece se contentar com a primeira etapa do modelo interpretativo de Dworkin, a etapa "pré-interpretativa", na qual de fato bastam os significados convencionais - ou melhor, parte-se dos acordos ("pré-interpretativos"!) de uma comunidade de intérpretes, de um vocabulário comum, de uma "forma de vida suficientemente concreta" (como formulado na referência de DWORKIN, 1986, p. 63, a Wittgenstein). O próprio Marmor (2005, p. 85-86; cf. DWORKIN, 1986, p. 90-91) enfatiza a necessidade desse acordo inicial sobre quais práticas contam como direito. Porém, se a teoria parar nesta fase - de reportar o pano de fundo compartilhado em uma comunidade -, não chegará a explicar a controvérsia sobre a qual os participantes de uma prática social disputam em determinado caso. Para tanto, seria preciso formular um ponto de vista crítico sobre a moralidade convencional ou o direito posto - e não simplesmente descrevê-los à maneira de um etnógrafo.

No exemplo do vegetariano, o observador simplesmente reportaria qual é a moral convencional (provavelmente, a do carnívoro). Mas o vegetariano apenas pode disputar sobre o que é moralmente correto, no caso, porque não se resume a conhecer uma convenção (o que é certo ou errado segundo a moralidade dominante), mas defende uma concepção alternativa, uma "moralidade concorrente", um argumento substancial de interpretação concorrente, e não apenas outra teoria sobre o que é o vegetarianismo (DWORKIN, 1972, p. 857-868; cf. DWORKIN, 1986, p. 64; 1982, p. 186). Nem o envolvido na controvérsia prática, nem o teórico que pretendesse compreendê-la estariam satisfeitos com a averiguação de fatos (o que é convencionalmente exigido, algo como uma pesquisa de opinião ou uma definição estipulativa). Além destes fatos, o prático e o 
intérprete têm que descobrir o valor que a prática consagra e, à luz dessa consideração, revisar o que a prática requer, formulando uma teoria coerente, com adequação (fit) à prática que quer explicar. Isto é o que as etapas "interpretativa" e "pós-interpretativa" acrescentam ao ponto de partida mínimo, "pré-interpretativo", do consenso ou convenção, a partir do qual os desacordos podem existir e a partir do qual podem ser avaliados.

O intérprete que Marmor propõe, caso queira explicar como os valores tornam algo exigível na visão dos participantes da prática, não terá sucesso em reportar adequadamente o desacordo, porque precisaria ele mesmo formar um juízo normativo sobre o que a prática requer para poder julgar o que os participantes julgam que ela requer - sem esta distinção, não há avaliação sobre a própria prática. Se quiser ascender a tal julgamento - para inclusive poder criticar as interpretações dos envolvidos na prática e no "desacordo teórico" (sobre o que a prática requer, não sobre fatos) -, o teórico precisará ele mesmo produzir uma interpretação que não é neutra, mas que concorre com a daqueles que ele observa (MACEDO JÚNIOR, 2013a, p. 237-238).

Um balanço do debate

É difícil avaliar o sucesso da empreitada de Marmor de defender o positivismo jurídico em contraposição com a teoria do direito de Dworkin. Em primeiro lugar, porque Marmor discute não só aspectos sensíveis de uma construção conceitual intrincada como a de Dworkin (por exemplo, dedicando um capítulo para a noção de "coerência" como ponte entre uma metodologia de interpretação jurídica e uma teoria da justiça de inspiração rawlsiana), mas também trata de diferentes versões do positivismo - notadamente, o de Hart e o de Raz. Em segundo lugar, como a teoria dworkiniana radicalizou a incorporação de pressupostos de filosofia da linguagem, do conhecimento e da verdade (além da filosofia moral e política) em sua própria construção, a empreitada de responder ao desafio de Dworkin (que Marmor interpretou como um desafio geral ao convencionalismo) fez Marmor transitar por muitas concepções que não são facilmente assimiláveis na teoria do direito.

Marmor (2005), de um lado, defende a excepcionalidade da interpretação e é forte na sustentação de uma explicação convencionalista da prática jurídica. Este é seu ponto de partida, enfatizado no capítulo 2 de Interpretação e teoria do direito (quando discute as teorias do significado) e constantemente reiterado, notadamente quando, já no capítulo 7, apela para Wittgenstein em defesa da distinção entre casos fáceis e casos difíceis com base na indeterminação da linguagem das regras. A interpretação, mais uma vez, surge como excepcional - e isto nos termos tradicionais do "convencionalismo" de Hart. Tal conclusão não afeta a teoria de Dworkin, que já havia apontado a centralidade 
dos casos em que surgem controvérsias teóricas e que não podem ser ignorados por uma teoria do direito (DWORKIN, 1986, p. 41-43).

A estratégia de defesa e ataque de Marmor, porém, não é linear. Se a interpretação é excepcional, não deixa de ser importante - Dworkin lança desafios sérios ao convencionalismo, admite. Então, de outro lado, como uma espécie de tese subsidiária, Marmor parece querer fornecer um ar "interpretativista" ao positivismo. Isto é exemplificável pela construção que Marmor (2005) oferece no capítulo 2, ainda antes de discutir a teoria de Dworkin em profundidade, de uma versão de interpretação baseada na atribuição de intenções a um autor fictício. É um modelo conversacional que guarda maior afinidade com a imagem positivista do direito baseado em fontes sociais, isto é, em decisões de autoridades. Essa afinidade fica ainda mais evidente quando Marmor apela para a teoria da autoridade de Raz, no outro extremo do livro (MARMOR, 2005, cap. 6).

Aqui o positivismo ou convencionalismo - a teoria do direito que se prende a fatos sociais, institucionais - aparece como fornecendo um método de interpretação sensato e complexo, capaz de concorrer com o método "construtivo" de Dworkin e de resistir às críticas de Dworkin às versões mais cruas de interpretação baseada na intenção das autoridades. E mais: o método marmoriano de interpretação assume ainda a exigência valorativa que Dworkin impõe ao direito - sustentar legitimidade política - e, para Marmor, cobre esta exigência com mais sucesso do que a interpretação "construtiva" ofertada por Dworkin, a qual apresentaria um deficit de legitimidade ao permitir que sejam incorporados ao direito padrões que não podem ser pensados como tendo sido desde o início criados como jurídicos ou juridicamente vinculantes.

Das cinco críticas que Marmor faz a Dworkin, na sistematização que foi apresentada, já apresentamos juízos sobre as três primeiras, mas retomemos a avaliação. Dworkin pode ter sido muitas vezes vacilante e pouco claro nas críticas ao "aguilhão semântico" do positivismo (DWORKIN, 1986, p. 45-46), que de fato não parece descritível como uma teoria sobre o significado da palavra "direito" ou sobre o uso dos termos jurídicos. A refutação de Marmor (2005, cap. 5) de que o positivismo de Hart possa ser algo como as teorias semânticas - "realistas", no sentido filosófico - é convincente. Também não parece que seja realmente desafiadora para Dworkin a ideia de que a interpretação "construtiva" - que requer algo mais do que decodificar textos de fontes formais - é excepcional no direito. Ainda, a crítica ao conceito de coerência pode retratar uma falha interna na teoria de Dworkin, mas pode também ser associada a uma má-compreensão de Marmor, especialmente se vista à luz daquelas duas críticas que destacamos com mais atenção: a crítica à rejeição da interpretação jurídica baseada nas intenções do autor/autoridade "construído" pelo intérprete e a crítica à "tese hermenêutica". Especialmente na crítica à "tese hermenêutica" e ao conceito de coerência, Marmor defende uma distinção que não cabe na teoria dworkiniana: uma distinção entre método e julgamento, entre descrição 
e avaliação. Dworkin preocupa-se em explicar o direito, o que o direito requer, e essa questão da teoria do direito é apenas uma versão mais geral (mas não qualitativamente diferente) da pergunta mais situada em uma disputa concreta: o que o direito requer? Por isso, a coerência é tanto um postulado metodológico quanto um valor de justiça política. A crítica à "tese hermenêutica" - de que teóricos e práticos concorrem no mesmo nível em seus argumentos avaliativos - parece iluminar mais claramente aquela crítica ao conceito de "coerência"; por isso, a crítica à "tese hermenêutica" é mais central do que a crítica à "coerência".

Ainda sobre as duas críticas que destacamos como centrais no debate, não nos parece que foram elaboradas de maneira suficientemente clara para que houvesse dificuldade em respondê-las por argumentos clássicos de Dworkin (a interpretação como elaboração de uma hipótese política sobre o direito; a concorrência entre interpretações teóricas e práticas sobre desacordos "teóricos").

Esta avaliação do debate não significa uma subscrição incondicional de Dworkin. Vista "sob a melhor luz", quer dizer - mais do que um apoio às teses de Dworkin ou um convencimento de que sua teoria vence definitivamente o positivismo - um não convencimento de que Marmor tenha avançado argumentos especialmente poderosos ou originais contra Dworkin ou em defesa do "convencionalismo". De Hart (1994a; 1994b) já se poderia extrair a defesa de que a interpretação é excepcional, de que casos difíceis, na "penumbra" da regra, é que geram indeterminação e de que esta é que gera a necessidade de interpretação em um sentido especialmente demandante, além do mero "aplicar" ou "seguir a regra". Uma noção definidora do positivismo é a ideia de que o direito tem que ser objeto de decisão de autoridade para que tenha legitimidade sobre os seus destinatários. Dworkin contra-atacou o positivismo justamente ao exigir que a justificação das decisões jurídicas jamais se expressasse como mera discricionariedade autorizadora de escolhas subjetivas; para levar o direito a sério, seria preciso sempre interpretá-lo como contendo - ainda que no plano tácito dos valores subjacentes a uma ordem jurídica - seus próprios parâmetros decisórios. Daí a necessidade de se formular juízos morais objetivos sob tais valores, garantindo a coerência desses valores com o corpo de direito interpretado e ancorando tais juízos neste direito.

São Paulo, 10 de abril de 2020.

\section{Referências}

AMATO, Lucas Fucci. As formas da sociologia do direito: uma redescrição luhmanniana do debate centenário entre Kelsen e Ehrlich. Nomos: Revista do Programa de Pós-Graduação em Direito da Universidade Federal do Ceará, Fortaleza, v. 35, n. 2, p. 227-254, jul./dez. 2015. 
AMATO, Lucas Fucci. Moralidade, legalidade e institucionalização: o debate Hart-Fuller. Revista de Direito da Universidade Federal de Viçosa, Viçosa, v. 11, n. 1, p. 335-360, 2019.

AMATO, Lucas Fucci. Realismo jurídico americano. In: CAMPILONGO, Celso Fernandes; GONZAGA, Alvaro de Azevedo; FREIRE, André Luiz (coord.). Enciclopédia Jurídica da PUCSP: Teoria Geral e Filosofia do Direito. São Paulo: PUC-SP, 2021. v. 2.

DWORKIN, Ronald. ¿Deben nuestros jueces ser filósofos? ¿Pueden ser filósofos? Traducción de Leonardo García Jaramillo. Isonomía, México, n. 32, p. 7-29, 2010. Disponível em: http://www. scielo.org.mx/pdf/is/n32/n32a1.pdf.

DWORKIN, Ronald. Hard cases. Harvard Law Review, Cambridge, MA, v. 88, n. 6, p. 1.057-1.109, Apr. 1975.

DWORKIN, Ronald. Hart's postscript and the character of political philosophy. Oxford Journal of Legal Studies, Oxford, v. 24, n. 1, p. 1-37, Mar. 2004.

DWORKIN, Ronald. Justice in Robes. Cambridge, MA: Harvard University Press, 2006.

DWORKIN, Ronald. Law as interpretation. Critical Inquiry, Chicago, v. 9, n. 1, p. 179-200, 1982.

DWORKIN, Ronald. Law's empire. Cambridge, MA: Harvard University Press, 1986.

DWORKIN, Ronald. Social rules and legal theory. The Yale Law Journal, New Haven, v. 81, n. 5, p. $855-890,1972$.

DWORKIN, Ronald. The model of rules. University of Chicago Law Review, Chicago, v. 35, n. 1, p. 14-46, 1967.

FULLER, Lon Luvois. Anatomy of the law. Middlesex: Penguin, 1971.

FULLER, Lon Luvois. Positivism and fidelity to law: a reply to professor Hart. Harvard Law Review, Cambridge, MA, v. 71, n. 4, p. 630-672, Feb. 1958.

GEERTZ, Clifford. O saber local: novos ensaios em antropologia interpretativa. Tradução de Vera Mello Joscelyne. Petrópolis: Vozes, 1997.

GEERTZ, Clifford. The interpretation of cultures: selected essays. New York: Basic Books, 1973.

HART, Herbert Lionel Adolphus. American jurisprudence through English eyes: the nightmare and the noble dream. In: . Essays in jurisprudence and philosophy. Oxford: Clarendon, 1983. p. $123-144$

HART, Herbert Lionel Adolphus. Positivism and the separation of law and morals. Harvard Law Review, Cambridge, MA, v. 71, n. 4, p. 593-629, Feb. 1958.

HART, Herbert Lionel Adolphus. Postscript. In: . The concept of law. 2. ed. Oxford: Clarendon, 1994b. p. 238-276.

HART, Herbert Lionel Adolphus. The concept of law. 2. ed. Oxford: Clarendon, 1994a. 
HERSHOVITZ, Scott. Wittgenstein on rules: the phantom menace. Oxford Journal of Legal Studies, Oxford, v. 22, n. 4, p. 619-640, Winter, 2002.

HIMMA, Kenneth Einar. Inclusive legal positivism. In: COLEMAN, Jules; SHAPIRO, Scott (ed.). The Oxford handbook of jurisprudence and philosophy of law. Oxford: Oxford University Press, 2002. p. 125-165.

HOBBES, Thomas. A dialogue between a philosopher and a student of the common laws of England. Chicago: University of Chicago Press, 1971.

HOLMES JR., Oliver Wendell. The path of the law. Harvard Law Review, Cambridge, MA, v. 10, n. 8, p. 457-478, Mar. 1897.

KANT, Immanuel. Groundwork of the metaphysics of morals. Translated and edited by Mary Gregor. Cambridge: Cambridge University Press, 1998.

MACEDO JÚNIOR, Ronaldo Porto. Do xadrez à cortesia: Dworkin e a teoria do direito contemporânea. São Paulo: Saraiva, 2013a.

MACEDO JÚNIOR, Ronaldo Porto. O direito em desacordo: o debate entre o interpretativismo e o convencionalismo jurídico. 2013. Tese (Titularidade em Filosofia e Teoria Geral do Direito) Faculdade de Direito, Universidade de São Paulo, São Paulo. 2013b.

MARMOR, Andrei. Exclusive legal positivism. In: COLEMAN, Jules; SHAPIRO, Scott (ed.). The Oxford handbook of jurisprudence and philosophy of law. Oxford: Oxford University Press, 2002. p. 104-124.

MARMOR, Andrei. Interpretation and legal theory. 2. ed. Oxford: Hart, 2005.

MICHELON JÚNIOR, Cláudio Fortunato. Aceitação e objetividade: uma comparação entre as teses de Hart e do positivismo precedente sobre a linguagem e o conhecimento do direito. São Paulo: Revista dos Tribunais, 2004.

RAZ, Joseph. Authority, law and morality. The Monist, Oxford, v. 68, n. 3, p. 295-324, July 1985.

RAZ, Joseph. Legal principles and the limits of law. The Yale Law Journal, Danvers, MA, v. 81, n. 5, p. 823-854, 1972.

SHAPIRO, Scott J. The "Hart-Dworkin" debate: a short guide for the perplexed. Michigan Law. Public Law and Legal Theory Working Paper Series, n. 77, p. 1-54, Mar. 2007. Disponível em: https://law.yale.edu/sites/default/files/documents/pdf/Faculty/Shapiro_Hart_Dworkin_Debate.pdf.

UNGER, Roberto Mangabeira. What should legal analysis become? London: Verso, 1996.

WITTGENSTEIN, Ludwig. Investigações filosóficas. Tradução de José Carlos Bruni. São Paulo: Nova Cultural, 1999. 